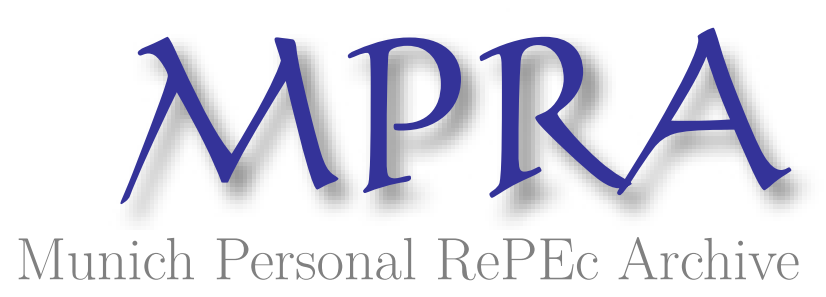

\title{
International Output Convergence, Breaks, and Asymmetric Adjustment
}

Dimitris, Chrsitopoulos and Miguel, Leon-Ledesma

Department of Economic and Refional Development, Panteion University

February 2009

Online at https://mpra.ub.uni-muenchen.de/14566/

MPRA Paper No. 14566, posted 11 Apr 2009 14:41 UTC 


\title{
International Output Convergence, Breaks, and Asymmetric Adjustment
}

\author{
Dimitris K. Christopoulos \\ Panteion University \\ Miguel A. León-Ledesma \\ University of Kent
}

\begin{abstract}
We present time series evidence on output convergence for 14 countries relative to the US for the 1900-2000 period. We develop tests that allow for an unknown number of breaks in the series and also asymmetric convergence speed. We show that this asymmetry arises theoretically when the economy is not in the neighbourhood of the steady state. Breaks are modelled through a Fourier function fitted to the deterministic part of a time series and asymmetries are modelled as a smooth transition function that matches the theory predictions. The tests are shown to have good finite sample properties. The results support the existence of convergence towards a mean that displays a break around WWII. These breaks, in the majority of cases, appear to be permanent. Asymmetric mean reversion also appears to be an important feature driving convergence for most countries in the sample. These results emphasize the importance that disruptive historical events have on the dynamics of relative outputs.
\end{abstract}

JEL codes: O47, C22

Keywords: time-series output convergence, Fourier model, asymmetric adjustment.

Acknowledgements: We would like to thank, without implicating, seminar participants at the University of Kent, University of Coimbra, the $2^{\text {nd }}$ OMD Meeting at CEDERS, Universite de la Mediterranee (Aix-en-Provence) and, especially, Karine Gente, Amanda Gosling, Hans-Martin Krolzig, Bryan Paterson, Gilbert Cette, Mathan Satchi and Katsuyuki Shibayama, for helpful discussions.

Address for correspondence: Miguel A. León-Ledesma, Department of Economics, Keynes College, University of Kent, Canterbury, Kent, CT2 7NP, UK. Phone: 0044 1227 823026. Fax: 00441227 827850. Email: M.A.Leon-Ledesma@kent.ac.uk 


\section{International Output Convergence, Breaks, and Asymmetric Adjustment}

\section{Introduction}

Theoretical models of growth have important implications for the stochastic behavior of income per capita differentials between countries. The standard neoclassical Solow-Swan model predicts that economies with identical determinants of steady state levels of income per capita would converge in the long run. The New Growth Theory models pioneered by Romer (1986) and Lucas (1988), predict that income per capita would diverge due to the non-convexities induced by physical and/or human capital. Tests of the convergence hypothesis are abundant in the literature (see the survey by Durlauf et al, 2006). Most of these tests have been carried out in cross-sectional contexts where convergence is interpreted as catching-up from initially poor to rich nations. The works of Bernard and Durlauf $(1995,1996)$ propose time-series definitions of the convergence hypothesis that are interpretable in terms of unit-roots and cointegration theory. According to these authors, convergence occurs when relative outputs are stationary with zero mean forecast value. $\mathrm{Li}$ and Papell (1999) considered also the possibility that the relative outputs are stationary with a positive mean (deterministic convergence). Pesaran (2007) has rationalized this possibility in the context of a neoclassical growth model. Within this framework, Evans (1998) claims that cross sectional studies generate inconsistent convergence rate estimates, which in turn would lead to incorrect inference regarding the neoclassical predictions. According to this author, time-series methods constitute a better way to test for output convergence.

The evidence on time series based tests mainly runs against the convergence hypothesis. The results presented in Bernard and Durlauf (1995) reject the hypothesis of unconditional convergence. Recently, Pesaran (2007) presents a pair-wise test and also 
rejects the existence of convergence in output levels. ${ }^{1}$ Cheung and Garcia-Pascual (2004) make use of panel data methods and conclude that the evidence depends on the null hypothesis in use, but their results for G7 countries are generally more supportive of convergence.

However, standard tests of time-series convergence suffer important shortcomings if structural breaks are present in the series. In this case, events that change the steady state levels of per capita income may change the mean towards which relative outputs would revert. This is the case in the works of Loewy and Papell (1996), Li and Papell (1999), Datta (2003), Landon-Lane and Robertson (2004) and Bentzen (2005) amongst others. When structural changes are present, standard tests of convergence may fail to reject the null of non-stationarity. If stationarity is found once breaks are controlled for, however, the results have to be interpreted as evidence that economies tend to converge but that the equilibrium has been affected by large exogenous events.

Another important aspect of these tests is that, as emphasized by Bernard and Durlauf (1996), they appear to be more appropriate when the time series are close to their invariant steady state. In that case, the stochastic properties of output would not be affected by initial conditions. Initial conditions, however, may matter when output is far away from steady state and is reflecting transitional dynamics. In the Solow-Swan growth model, the speed of convergence outside the neighborhood of steady state is not constant. We show that the speed of convergence will be higher (lower) when the economy approximates its steady state from below (above). Hence, if historical output series experience large shocks to relative output, it is unlikely that the assumption of no transitional dynamics will hold for all the sample period. In this case, mean reversion of relative output will depend on the relative position of the economy with respect to its (possibly time varying) equilibrium.

In this paper we develop innovative tests for time-series output convergence based on the unit root literature that allow, simultaneously, for the series to have an unspecified

\footnotetext{
${ }^{1}$ See also Camarero et al (2002) for Mercosur countries.
} 
number of structural breaks and the possibility that the speed of mean reversion is not constant thus obeying the theoretical predictions of the model outside the steady state neighborhood. Structural changes are captured by means of a Fourier function fitted to the deterministic components of relative output as in Becker et al (2006). This Fourier function allows us to endogenously differentiate between permanent and temporary breaks. Asymmetric mean reversion is captured by a logistic smooth transition function fitted to the residuals of the Fourier model. We develop critical values for two versions of the unit root test that depend on the frequency of the breaks in the Fourier function. We show that the tests have satisfactory size and power properties. When we apply the tests to the income per capita of 14 developed countries relative to the US using 100 years of data, we can reject the null of a unit root in all cases except Japan. There is widespread evidence of a structural change following the 1920s depression or World War II. This alone accounts for a large part of the rejections of the unit root null in the sample and is evidence of deterministic convergence to a non-constant mean. We also find strong evidence that the speed of convergence is not constant, which allows us to classify periods depending on the speed of convergence. Regarding the performance of this group of economies relative to the US, countries can be classified in three groups: i) a group of countries experiencing a "falling-behind" process (UK and Australia); ii) a group of countries whose relative output has remained relatively constant throughout the century (mostly European countries plus Canada); a group experiencing a fast process of catching-up (Japan, Italy, and the Scandinavian countries).

The paper is organized as follows. Next section discusses the definitions of convergence in the literature and the issue of breaks and asymmetry. Section 3 presents the unit root test and its size and power properties. Section 4 presents the results for relative per capita incomes. Section 5 concludes.

\section{Output convergence in time-series}

As mentioned in the introduction, the concept of per-capita income convergence in time series relates to the integration properties of relative output per-capita levels. Bernard and 
Durlauf $(1995,1996)$ define convergence in output ${ }^{2}(y)$ between a pair of countries $i$ and $j$ as implying that the long-term forecasts of output for both countries are equal at a fixed time $t$ so that:

$\lim _{k \rightarrow \infty} E\left(y_{i, t+k}-y_{j, t+k} \mid I_{t}\right)=0$

Equation (1) equates the notion of convergence with the tendency of output per capita differentials to disappear as the forecast horizon increases. From an empirical point of view the time series notion of convergence requires that per capita output differentials between countries $i$ and $j$ be zero-mean stationary. If output per capita series are trend stationary, definition (1) implies that the time series trends for each country must be identical. In the multivariate case, pair-wise convergence must hold for all pairs of sampled countries. Definition (1) would hold if relative incomes are compatible with a time-invariant Wold representation of the form

$y_{i, t}-y_{j, t}=\kappa_{i, j}+\sum_{r=0}^{\infty} \lambda_{i, j, r} \varepsilon_{i, j, t-r}$

such that $\kappa_{i, j}=0$ and $\lambda_{i, j, r}$ is square-summable, with $\varepsilon_{i, j, t-r}$ being error terms [Bernard and Durlauf, 1996].

The requirement that relative output is zero-mean stationary may be imposing too strong requirements on convergence. As discussed by Pesaran (2007), a zero mean would imply that two economies are identical in every respect, including savings rates, population growths and initial endowments. For this reason, a less stringent version of output convergence in time-series can be defined as deterministic convergence. This requires that relative output is level stationary but not necessarily zero-mean. This definition follows Li and Papell (1999) and is based on Ogaki and Park (1998). It then implies that:

\footnotetext{
${ }^{2}$ Output here refers to the log of per capita output.
} 
$\lim _{k \rightarrow \infty} E\left(y_{i, t+k}-y_{j, t+k} \mid I_{t}\right)=\alpha_{i j}$

with $\alpha_{i j}$ being either a constant or a time-varying (breaking) parameter. Note that in this case $\kappa_{i, j}$ in (2) would be different from zero. Nevertheless, definition (3) still implies that, for a sample period $T$, the average rate of growth differential between the two countries, $T^{-1} \sum_{t=1}^{T} \Delta y_{i, t}-T^{-1} \sum_{t=1}^{T} \Delta y_{j, t}$, is zero-mean stationary. This means that this difference does not depend on the (constant) differences in initial output, which is the cross-sectional definition of convergence. ${ }^{3}$

These definitions have a clear counterpart in the unit-root and cointegration literature. Output convergence would imply that relative outputs are $\mathrm{I}(0)$ variables so that a shock does not have a permanent effect on output differences. The results from the early literature run against the convergence hypothesis. Recently, however, several authors have recognized the importance that structural breaks in the series, due to events such as the Great Depression or World War II, can have on unit root tests. It is a standard result in the literature that breaks increase the probability of accepting the null of a unit root when the series behaves as stationary around a breaking mean. If this happens, assuming a constant $\alpha_{i j}$ in (3) could spuriously lead to over-acceptance of the null of a unit root as the sample mean of $y_{i, t}-y_{j, t}$ may not be unique for all the sample period. This is the case in, amongst others, Loewy and Papell (1996), Li and Papell (1999), Datta (2003) and Bentzen (2005) who find more supportive evidence in favor of deterministic convergence in different contexts. ${ }^{4}$ Landon-Lane and Robertson (2004) find that convergence amongst OECD countries is a very sample-specific phenomenon that only appears to occur between World War II and the first oil shock. In this case, the convergence hypothesis

\footnotetext{
${ }^{3}$ Carlino and Mills (1993) define "stochastic convergence" as relative outputs being trend-stationary. However, this would imply that $\kappa_{i, j}$ has a trend and hence there is a constant difference in the average rates of growth of relative outputs. This would match with the standard cross-sectional definition of $\beta$ convergence, but not with time-series convergence, as relative growth would depend on the constant initial differences in output.

${ }^{4}$ See also Carvalho and Harvey (2005), Luginbuhl and Koopman (2004) and St. Aubyn (1999) for different approaches to convergence based on structural time series models and the Kalman filter.
} 
has to be "qualified", as it would imply convergence once the test takes into account breaks that are produced by some exogenous events. In this case the change in the mean of relative outputs itself is of economic interest as it has consequences for the equilibrium relative output levels. Countries may have experienced processes of, for instance, technological catch-up or falling behind that may have changed their equilibrium relative output levels. Hence, whether the breaks in the series are permanent or transitory is also an economically relevant area of analysis. Notwithstanding these caveats, this qualified deterministic convergence hypothesis still has important theoretical implications.

Large shocks to the output series, however, may also have another impact on convergence tests. A large shock generated by an important disruption to economic activity could potentially destroy existing capital stock in the economy, moving it away from its steady state equilibrium. This would imply that for certain periods following large shocks, the speed of mean reversion in the time-series of relative outputs changes as the data captures the impact of transitional dynamics when the economy is far from equilibrium. As shown by Barro and Sala-i-Martin (2004) ${ }^{5}$ and discussed in depth by Mathunjwa and Temple (2006), outside the neighborhood of the steady state the speed of mean reversion will depend on the distance between the current and the steady state level of capital stock (output). Usually, mean reversion is analyzed in theory models by linearizing around the steady state. In that case it is safe to assume a constant speed of mean reversion. However, it is easy to show that the speed of mean reversion depends on the distance between output and its steady state value. To make this point more transparent, assume an economy where output is produced by the following CobbDouglas production function:

$Y_{t}=K_{t}^{\alpha}\left(A_{t} L_{t}\right)^{1-\alpha}$

where $K_{t}$ is capital. Labor $\left(L_{t}\right)$ and technology $\left(A_{t}\right)$ evolve according to the following deterministic paths: 
$L_{t}=(1+n) L_{t-1}$

$A_{t}=(1+g) A_{t-1}$

where $n, g>0$ are population growth and the rate of technical progress respectively. Capital depreciates at a constant rate $\delta$ and the savings rate $s$ is constant so that $K_{t}=s Y_{t-1}+(1-\delta) K_{t-1}$. Defining capital and output per effective worker as $k_{t}=\frac{K_{t}}{A_{t} L_{t}}$ and $y_{t}=\frac{Y_{t}}{A_{t} L_{t}}$ respectively, the steady state levels of capital and output per effective worker are: 6

$k^{*}=\left(\frac{s}{n+g+\delta}\right)^{\frac{1}{1-\alpha}}$

$y^{*}=\left(\frac{s}{n+g+\delta}\right)^{\frac{\alpha}{1-\alpha}}$

The dynamics of $k$ outside steady state are described by the following difference equation:

$k_{t}-k_{t-1}=\Delta k_{t}=s k_{t-1}^{\alpha}-(n+g+\delta) k_{t-1}$

Given that $\Delta \log k_{t}=\Delta k_{t} / k_{t-1}$, from the production function we have that $\Delta \log y_{t}=\alpha \Delta \log k_{t}$. This, together with (6) allows us to write the rate of growth of output outside the steady state as:

$\Delta \log y_{t}=\alpha\left[s y_{t-1}^{(\alpha-1) / \alpha}-(n+g+\delta)\right]$

${ }^{5}$ See Barro and Sala-i-Martin (2004) page 78.

${ }^{6}$ We assume that $n$ and $g$ are small enough so that $g \cdot n \approx 0$. 
From the steady state value for $y_{t}$ given in (5), we can obtain an expression for the savings rate as a function of steady state output as $s=(g+n+\delta) y^{*(1-\alpha) / \alpha}$, which we can substitute into (7) to obtain:

$$
\Delta \log y_{t}=\alpha(n+g+\delta)\left[\left(y_{t-1} / y^{*}\right)^{-(1-\alpha) / \alpha}-1\right]
$$

This expression allows us to obtain a measure of the speed of convergence towards the steady state which is defined as:

$\beta=-\frac{\partial\left(\Delta \log y_{t}\right)}{\partial \log y_{t-1}}=(1-\alpha)(g+n+\delta)\left[y_{t-1} / y^{*}\right]^{-(1-\alpha) / \alpha}$

Hence, the speed of convergence in the neighborhood of the steady state, when $\left[y_{t-1} / y^{*}\right]=1$ is the familiar expression $\beta^{*}=(1-\alpha)(g+n+\delta)$. However, outside the steady state $\beta$ will be higher (lower) than $\beta^{*}$ as the economy approaches the steady state from below (above). ${ }^{7}$ To illustrate this point, Figure 1 presents the evolution of $\beta$ against $\left[y_{t-1} / y^{*}\right]$ for values of the parameters given as $n=0.01, g=0.02, \delta=0.05$ and $\alpha$ $=1 / 3$. This result shows that if for some periods the economy is far away enough from the steady state, the speed of adjustment will be asymmetric.

The evolution of output per capita $\tilde{y}_{t}=Y_{t} / L_{t}$ is then given by the following partial adjustment equation: ${ }^{8}$

$\Delta \log \tilde{y}_{t}=\beta \log \left(A_{0}\right)-\beta g+\beta \tilde{y}_{t-1}+\beta g t+\beta\left(\frac{\alpha}{1-\alpha}\right)[\log s-\log (n+g-\delta)]$

\footnotetext{
7 Notice that equation (9) can also be expressed in terms of the log of output as $\beta=\beta^{*}\left[e^{[(1-\alpha) / \alpha] \log \left(y_{t-1} / y^{*}\right)}\right]^{-1}$, which may be more useful for empirical purposes when working with logarithmic values.

${ }^{8}$ Here we make use of the fact that $A_{t}=(1+g)^{t} A_{0} \square A_{0} e^{g t}$.
} 
which implies that the log of output per capita converges to:

$\log \tilde{y}_{t}=\log \left(A_{0}\right)-g+g t+\left(\frac{\alpha}{1-\alpha}\right)[\log s-\log (n+g-\delta)]$

This is a familiar result from Binder and Pesaran (1999) and Pesaran (2007) but in a deterministic setting. Hence, two economies identical in every respect will converge to the same steady state and the Bernard-Durlauf definition of convergence would hold. Assuming a common technical progress parameter, two economies can converge to a constant relative output differential if $A_{0}, \alpha, n, s$, or $\delta$ differ. Given the potential instability of parameters of the model, this constant mean may be subject to temporary or permanent structural breaks as acknowledged by previous studies.

Hence, when testing for unit roots in relative output, it is necessary to consider both, structural breaks and the asymmetry in the speed of convergence that depends on the distance from steady state. Failure to consider these aspects in unit root tests would lead to a large loss of power and the consequent over-acceptance of the null of noconvergence. In the following section we develop unit root tests that allow for an unknown number of breaks and possibly asymmetric mean reversion. These tests are then applied to a century of data for 14 countries relative to the US.

\section{Unit root tests}

The basic idea behind the tests developed in this section is to use trigonometric variables to capture breaks or large non-linearities in the deterministic terms of the variable together with smooth transition functions that allow capturing asymmetric adjustment to the deterministic trend. These tests can be considered as alternatives to Perron (1990), Zivot-Andrews (1992) and Bai and Perron (1998) that also allow for asymmetries in the adjustment speed. This asymmetric adjustment speed is consistent with that derived from 
the theory model. An additional advantage of the tests is that they provide us with a simple way to analyze whether the breaks are permanent or transitory.

Consider the following model for a stochastic variable $y_{t}$

$y_{t}=\delta(t)+v_{t}$,

where $v_{t} \sim N(0, \sigma)$ and $\delta(t)$ is a time-varying deterministic mean. Following Becker et al. (2004) and Becker et al (2006) we use a Fourier series expansion to approximate the unknown number of breaks of unknown form $\delta(t)$ as

$\delta(t)=\delta_{0}+\sum_{k=1}^{G} \delta_{1}^{k} \sin \left(\frac{2 \pi k t}{T}\right)+\sum_{k=1}^{G} \delta_{2}^{k} \cos \left(\frac{2 \pi k t}{T}\right)$

where $k$ is the number of frequencies of the Fourier function, $t$ is a trend term, $T$ is the sample size and $\pi=3.1416$.

When $G$ is large, then the unknown functional form $\delta(t)$ can be approximated very well. In the case where the null hypothesis $\delta_{k}=0$ is rejected for at least one frequency $k=G_{1}, \ldots, G_{M}$ with $G_{1}>0$, then the nonlinear component can explain adequately the deterministic component of $y_{t}$ and at least one structural change is present in the DGP. Otherwise the linear model without any structural change emerges as a special case. Note that in this specification the breaks are modeled as smooth processes rather than level shifts, but would have the same economic interpretation.

A specification problem related with model (13) is to identify the appropriate number of frequencies to include in the fitted model. In dealing with this issue we follow Ludlow and Enders (2000) who showed that a single frequency is enough to approximate the Fourier expansion in empirical applications. Thus, equation (13) can be written as 
$\delta(t)=\delta_{0}+\delta_{1} \sin \left(\frac{2 \pi k t}{T}\right)+\delta_{2} \cos \left(\frac{2 \pi k t}{T}\right)$

According to Becker et al. (2004) equation (12) under specification (14) has more power to detect several smooth breaks of unknown form in the intercept than the standard Bai and Perron (2003) multi-break tests.

If the appropriate frequency $k$ was known then we would be able to test for the presence of unknown structural breaks in the baseline equation (12). However, the true value of $k$ is typically unknown. A standard way to find out the most appropriate frequency $k$ is to estimate equation (12) under definition (14) for each value of $k$ within a certain interval. According to Becker et al (2006), since the breaks shift the spectral density function towards frequency zero, the most appropriate frequency interval for a break is likely to be at the low end of the spectrum. Thus, it is the low frequencies that are the most appropriate to use for a test of unit root versus stationarity, as these would represent structural breaks rather than short-run cyclical behavior. Hence, the value of $k$ is then chosen using the Bayesian Information Criterion (BIC). In our application we used an interval for $k=[0.1,0.2, \ldots, 4.9,5]$.

Testing for the presence of unknown (smooth) breaks in the DGP of $y_{t}$ can then be carried out by using the null hypothesis $H_{o}: \delta_{1}=\delta_{2}=0$ against the alternative $H_{1}: \delta_{1}=\delta_{2} \neq 0$. A $F$-statistic can be employed to test this null hypothesis. Monte Carlo simulations that approximate the empirical distribution for this test are tabulated in Becker et al (2006). It should be noted that since the $F$-statistic has low power if the data are non-stationary this could be used only when the null of a unit root is rejected.

Note that the Fourier transform implies that if we select an integer frequency, the function would be such that the breaks are temporary. Fractional frequencies would imply permanent breaks as the function would not complete a full oscillation. Whether the permanent break is positive or negative will depend on the values of $\delta_{1}$ and $\delta_{2}$. This is 
illustrated in Figure 2, where we plot three Fourier functions for different values of $k, \delta_{1}$, and $\delta_{2}$ for $T=100$. The non-integer values of $k$ generate permanent breaks in the series, whereas for $k=1$ we have only temporary breaks. This can be important in the output convergence context as it allows checking if the breaks led to permanently higher or lower relative per capita income. Countries that embarked in a process of important structural transformations after WWII, for instance, may have experienced rapid catch-up processes affecting their steady state output levels. ${ }^{9}$ In function (14), for a particular frequency $k$, the sign of coefficients $\delta_{1}$ and $\delta_{2}$ determines whether the country shows stable relative output, relative decline (falling behind), or relative catch-up throughout the sample. ${ }^{10}$ This can be simply analyzed by looking at the selected optimal frequency and the individual significance of coefficients $\delta_{1}$ and $\delta_{2}$.

Within this context, given the model

$y_{t}=\delta_{0}+\delta_{1} \sin \left(\frac{2 \pi k t}{T}\right)+\delta_{2} \cos \left(\frac{2 \pi k t}{T}\right)+v_{t}$,

the null unit root hypothesis of interest can then be stated as follows:

$H_{0}: v_{t}=\mu_{t}, \quad \mu_{t}=\mu_{t-1}+h_{t}$

where $h_{t}$ is assumed to be a stationary process with zero mean. The test statistics we propose are then calculated via a three step procedure:

\footnotetext{
${ }^{9}$ This is in fact related to the catch-up definition of Bernard and Durlauf (1996) (Definition 1 in their paper).

${ }^{10}$ For instance, for a frequency of 0.5 , stable relative output would arise if $\delta_{2}=0$, relative decline if $\delta_{2}>0$, and catching-up if $\delta_{2}<0$ (regardless of the values of $\delta_{1}$ ). This is not, however, a general rule, as it will depend on the frequency $k$.
} 
The first step involves finding the optimal frequency $k^{*}$ and estimating the non-linear deterministic component in model (15) by OLS as explained above. We then compute the OLS residuals

$$
\hat{v}_{t}=y_{t}-\left[\hat{\delta}_{0}+\hat{\delta}_{1} \sin \left(\frac{2 \pi k^{*} t}{T}\right)+\hat{\delta}_{2} \cos \left(\frac{2 \pi k^{*} t}{T}\right)\right] \text {. }
$$

In the second step we test for a unit root on the OLS residuals of step one. Given that, as discussed in the previous section, mean reversion may present asymmetric features, we propose the following two linear and non-linear models:

$$
\Delta v_{t}=\alpha_{1} v_{t-1}+\sum_{j=1}^{p} \beta_{j} \Delta v_{t-j}+u_{t}
$$

$$
\Delta v_{t}=\rho v_{t-1}\left(1+\exp \left(\theta v_{t-i}\right)\right)^{-1}+\sum_{j=1}^{p} \alpha_{j} \Delta v_{t-j}+u_{t} \quad i=1,2, \ldots . . L
$$

where $\theta>0$ and $u_{t}$ is a white noise error term.

If we reject the null of a unit root in step two, the third step consists of testing for $H_{o}: \delta_{1}=\delta_{2}=0$ against the alternative $H_{1}: \delta_{1}=\delta_{2} \neq 0$ in (15). If the null hypothesis is rejected, we can conclude that the variable is stationary around a nonlinear deterministic function.

Model (16) is a standard ADF regression, which we call Fourier-ADF (FADF), while model (17) assumes that the adjustment speed is asymmetric and follows a Logistic Smooth Transition Autoregressive (LSTAR) process. Model (17) corresponds to the unit root tests developed by Park and Shintani (2005). Both models allow for testing for a unit root in the original series after removing the breaks in the deterministic component. In the 
linear case, the null unit root hypothesis $H_{0}: \alpha_{1}=0$ is tested against the alternative $H_{0}: \alpha_{1} \neq 0$.

Model (17) allows, in addition to nonlinear deterministic trends, testing for a unit root against a non-linear alternative in which the speed of mean reversion depends on the distance from equilibrium. In particular in the model suggested by Park and Shintani (2005) the transition parameter $\theta$ determines the speed of transition between two extreme regimes. The logistic transition function $F\left(\theta, v_{t-i}\right)$ is bounded by zero and unity with $v_{t-i}$ being the transition variable that determines the regime. If $\theta \rightarrow 0$ model (17) becomes linear $v_{t}=v_{t-1}+0.5 \rho v_{t-1}+u_{t}$ while as $\theta \rightarrow \infty$ the transition function approaches a heavy-side function, taking the value 1 for $v_{t-i}<0$ and 0 for $v_{t-i}>0$. The corresponding $\mathrm{AR}(1)$ models are given by $v_{t}=v_{t-1}+u_{t}$ for $v_{t-i}>0$ and $v_{t}=(1+\rho) v_{t-1}+u_{t}$ for $v_{t-i}<0$ respectively. This logistic function allowing for different effects of positive and negative deviations from equilibrium implies that the speed of mean reversion depends on whether the transition variable is above or below the steady state. This specification matches the theoretical form of the speed of convergence outside steady state. The speed of convergence in the neighborhood of the steady state (when $\left.v_{t-i}=0\right)$ would be equal to $0.5 \cdot \rho$ and it increases (falls) as $v_{t-i}<0\left(v_{t-i}>0\right)$. Here $v_{t-i}$ represents deviations from equilibrium as it is the demeaned log value of relative output. $^{11}$

To test the null unit root hypothesis, Park and Shintani (2005) have proposed the following infimum $t$-statistic

$\inf -t=\inf _{\theta \in \Theta} T(\theta)$

\footnotetext{
${ }^{11}$ In the theory model $\beta$ in equation (9) is bounded between $+\infty$ and 0 . Our function is bounded between 1 and 0 , as for estimation purposes the transition function needs to be finitely bounded. However, the two transition functions are very close (see footnote 7) for reasonable values of deviations from steady state.
} 
where the function $T(\theta)=\frac{\hat{\rho}(\theta)}{\text { s.e. }(\hat{\rho}(\theta))}$ is the t-ratio test for the null hypothesis $\mathrm{H}_{0}: \rho=0$ for the range of values of $\theta$ defined as $\Theta=[\underline{\theta}, \bar{\theta}]$ and $0<\underline{\theta}<\theta<\bar{\theta}$. The value of $\theta$ can be estimated by using $\hat{\theta}=\underset{\theta \in \Theta}{\arg \min } T(\theta)$ over the parameter space $\left[\frac{1}{10} Q, 10^{3} Q\right]$, where $Q=\left(\frac{1}{\sqrt{\sum_{t=1} v_{t}^{2} / T}}\right)$. Hence the inf $-t$ test is the minimum value of the (negative) t-ratios for the unit root null evaluated over a range of values of the transition speed parameter. ${ }^{12}$

Becker et al (2006) have shown that when a Fourier function is adopted in the first stage then the asymptotic distribution of any unit root test implemented in the second stage depends only on the frequency $k$ of the Fourier series. We tabulated critical values for the two tests via Monte Carlo simulations under the null of a random walk for values of $k$ between 0.5 and 3 at increments of 0.5 and sample sizes of 100, 250 and 500 observations. The critical values were obtained from 10,000 replications using a pseudorandom number generator. These critical values are reported in Tables $\mathbf{1}$ and $\mathbf{2}$.

\subsection{Size and power properties}

We carry out a Monte Carlo experiment in order to investigate the small sample size and power properties of the tests suggested in the previous Section. In all Monte Carlo simulations the parameter space is set equal to $\left[\frac{1}{10} Q, 10^{3} Q\right]$, where $Q=\left(\frac{1}{\sqrt{\sum_{t=1} v_{t}^{2} / T}}\right)$.

We first consider the size of the tests using the following non-stationary DGP

$y_{t}=\delta_{0}+\delta_{1} \sin \left(\frac{2 \pi k^{*} t}{T}\right)+\delta_{2} \cos \left(\frac{2 \pi k^{*} t}{T}\right)+v_{t}$

\footnotetext{
${ }^{12}$ See Park and Shintani (2005) for a detailed analysis of the parameter space for $\theta$.
} 
$v_{t}=v_{t-1}+\varepsilon_{t}$

where $\varepsilon_{t}$ is a sequence of standard normal errors and $k^{*}$ stands for the optimal frequency.

The empirical size is considered for each test for sample sizes $T=\{100,250\}$, values of $k^{*}=\{0.5,1,1.5,2.5\}$ and $\delta_{1}=\delta_{2}=\{1,0.5,0.1\}$ with a nominal size of $5 \%$. The results are displayed in Table 3. We can see that both tests display empirical sizes that are very close to the nominal. The inf $-t$ test performs better than the FADF statistic when $T=100, \delta_{1}=\delta_{2}=1$ and $k^{*}=0.5,1,1.5$. In these cases the FADF test tends to slightly under-reject. The FADF test has less size distortions than the inf $-t$ when $\delta_{1}=\delta_{2}=0.1$ for all $k^{*}$ and when $\delta_{1}=\delta_{2}=0.5$ and $k^{*}=0.5,1$. When the sample size is increased to $T=250$ the inf $-t$ performs better than the FADF statistic for high and moderate values of $\delta_{1}=\delta_{2}=0.1,0.5$ irrespective of the values of $k^{*}$ while for low values of $\delta_{1}=\delta_{2}=0.1$ the FADF outperforms the inf $-t$ statistic, which tends to slightly over-reject. Overall, we can conclude that the FADF test has marginally better size properties relative to the inf $-t$ test for low values of $\delta_{1}=\delta_{2}=0.1$. On the other hand, for high and moderate values of $\delta_{1}=\delta_{2}=0.1,0.5$ (i.e. larger amplitudes of the oscillations) the inf $-t$ test performs better than the FADF. In general, these results show that the 3-steps procedure employed does not produce excessive rejections of the unit root null when it is true, which ensures that the test is not over-fitting deterministic components that could lead to over-rejection.

To check the robustness of our findings, the empirical size of the tests was also simulated for two cases with non-normal errors. In particular, we considered errors $\left(\varepsilon_{t}\right)$ drawn form both the $\chi^{2}(1)-1$ distribution and the $t(6)$ distribution. In both cases the simulation results indicated that both tests are robust against both types of non-normal 
errors. In all the cases the empirical sizes were very close to the nominal for all sample sizes using the critical values of Tables 1 and $2 .^{13}$

Next, we investigate the power properties of the unit root tests against a globally stationary process using the following Fourier-LSTAR model as a DGP:

$y_{t}=\delta_{0}+\delta_{1} \sin \left(\frac{2 \pi k^{*} t}{T}\right)+\delta_{2} \cos \left(\frac{2 \pi k^{*} t}{T}\right)+v_{t}$

$v_{t}=v_{t-1}+\rho v_{t-1}\left(1+\exp \left(\theta v_{t-1}\right)\right)^{-1}+u_{t}$,

where $u_{t}$ is a sequence of standard normal errors. All combinations of the following parameter values and frequencies were used: $\rho=\{-1.5,-1,-0.5,-0.1\}, \theta=\{0.01,0.5,1\}$, $\delta_{1}=\delta_{2}=\{1,0.1\}$ and $k^{*}=\{0.5,1,1.5,2.5\}$. The results from these power experiments for a sample size of 250 are shown in Table 4. The general outcome is that for values of $\delta_{1}=\delta_{2}=1$ the inf $-t$ test is more powerful than the simple FADF test irrespective of the values of $k^{*}$ and $\rho$. The power of the inf $-t$ test increases for high and moderate values of $\rho=\{-1.5,-1.0,0.5\}$ and low values of $\theta=\{0.5,1\}$. This is not unexpected since as $\rho$ increases, for a given $\theta$ the process becomes less persistent. On the other hand for a given $\rho$ as $\theta$ decreases $\left(1+\exp \left(\theta v_{t-i}\right)\right)^{-1}$ increases and the process tends to be less persistent. The power of the inf $-t$ test tends to unity for high values of $\rho=\{-1.5,-1\}$ and $\theta=\{0.01,0.5\}$ while the power of the FADF test approaches unity for $\rho=\{-1.5,-1\}$ and $\theta=\{0.01\}$. These conclusions also apply for the case where $\delta_{1}=\delta_{2}=0.1$. In general, thus, the inf $-t$ test is more powerful than the FADF test in all cases, and the difference in terms of power gains increases as the process becomes more persistent.

\section{Results}

\footnotetext{
${ }^{13}$ These findings are not reported here to save space but are available from the authors upon request.
} 
We tested for deterministic output convergence relative to the US in a dataset of 14 developed countries for the 1900-2000 period. The data was obtained from Maddison $(1995)^{14}$. We used the difference in the logs of per capita output of country $j$ relative to the US. The data is plotted in Figure 3. We can observe that this group of countries shows a variety of patterns in the behavior of relative output. Several of them experience a substantial process of catching-up like Japan, Finland and Norway. Others have clearly fallen behind (Australia and the UK) while a large group seems to have experienced little change in relative output throughout the century. The main common pattern appears to be the major breaks occurring during World War II (WWII). For some European countries, convergence to appears to be faster during the inter-war period and the Great Depression. After WWII there is a process of slow convergence that levels-off (and even slightly reverses) towards the end of the period when US growth outperformed other OECD countries. Exceptions to this pattern appear to be Australia, the UK and Canada. For Australia and the UK the post-War era did not lead to a convergence pattern, but rather stagnant differences in output. Canada appears to have experienced the major break before 1920. Overall, relative outputs do not show a monotonic pattern of convergence, but are affected by large breaks and shocks that should be accounted for when testing for convergence.

We first applied standard ADF unit root tests on the original relative output data. The results, in accordance with previous studies, showed that only for Canada and the Netherlands we were able to reject the null of a unit root including a constant in the deterministic components. When no constant was used, we could only reject a unit root for the Netherlands.

We hence proceeded to fit a Fourier model to the series, as explained above, setting the maximum $k$ to 4 . We used increments of 0.1 for the search of the optimal frequency. Not surprisingly, given the behavior of the series, for 12 out of 14 countries the frequency was found to be less than 2 and in most cases close to 1 (see Table 5 column 2). For France a frequency of 1 indicates only a temporary break. Exceptions are Denmark and

\footnotetext{
${ }^{14}$ This data set can be downloaded at Maddison's website: http://www.ggdc.net/maddison/
} 
Germany where the relevant frequencies were equal to 2.90 and 3.60 respectively. This reveals that in most cases there was usually only one major event that affected the sample mean of output differences, i.e. one structural break. Figure 4 plots output and the estimated Fourier function for the 14 countries in the sample. For many countries, as expected, the Fourier function shows a minimum around the WWII period. Given that the destructive effects of war were felt mainly in European countries and Japan but they did not affect substantially the US, WWII reduced dramatically relative income per capita in these countries. There are, however, specificities to the patterns of breaks experienced by many of the countries:

- Finland and Sweden experienced a dip in output during the decade of the 1920s. Finland became independent from the Soviet Union in 1918, but a civil war ensued that is reflected in a rapid output decline. Sweden was hit very badly by an attempt of Socialist revolution in 1917 and the 1920s recession.

- Canada's break appears during the 1930s. This seems to reflect the effect of a large negative shock during WWI and relative stagnation until the post-WWII period.

- In the UK and Australia, the dominant feature is the decline in relative output experienced throughout the period. After WWII, both countries appear to be locked into levels of relative per-capita income substantially below those before the 1940s. This relative decline levels off by the end of the 1970s.

- Denmark's output fell during WWI and then recovered quickly until WWII. Afterwards we observe a recovery until the early 1970s and a small relative decline until the final years of the sample. In the case of Germany a similar pattern arises, although the last fluctuation of the Fourier function appears to be out of synchrony with the relatively constant levels of relative output since the 1970s.

- Finally, both Japan and Norway have experienced an almost continuous increase in relative output since WWII. 
In general, our results show that major events such as WWII and the 1920s depression are crucial in understanding pair-wise convergence with the US and are driving a good part of the dynamics of output. Our results look remarkably similar to those in $\mathrm{Li}$ and Papell (1999) and are in accordance with those in Landon-Lane and Robertson (2004). We can further analyze the properties of the Fourier function to classify countries according to their economic performance during the $20^{\text {th }}$ century. Table 6 shows the estimated coefficients of the Fourier function. The last column shows a $(+)$ sign if the country experienced a statistically significant catch-up process, an $(=)$ sign for constant relative output and a (-) for cases of relative decline. In cases where these changes have been minor (defined as less than a $10 \%$ change), we follow the sign with the $(=)$ symbol. Figure 4 plots output and the Fourier function by groups of countries. The first row shows the two relative decliners (Australia and the UK) where growth rates appear to be parallel to that of the US but with WWII leading to a substantial divergence in per-capita income levels. The next three rows show the group of countries whose relative output did not experience any large change, which is made up of core European countries plus Canada. The last three rows show the catch-up group, made up of Italy, Scandinavian countries, and Japan.

The next step consists of obtaining the residuals from the Fourier function and applying the two unit root tests explained in the previous section. The inf $-t$ statistic was computed for $v_{t-i}, i=1,2,3,4$. and the model with the smallest SSR was selected. The results are reported in columns 4 to 7 in Table 5. The FADF test is now able to reject the null of a unit root in ten out of fourteen countries. That is, breaks alone appear to account for a good part of the acceptances of the null of a unit root in a linear model. However, the unit root null is still not rejected for Austria, Germany, Japan and Italy and for Finland and the UK the rejection is only at the $10 \%$ level. When applying the inf $-t$ test, though, the null of a unit root is rejected in all cases except for Japan. ${ }^{15}$ The values of parameter $\rho$ are also reported in the table. Note that for values of relative output close to the (time varying) mean the speed of mean reversion is equal to $\rho / 2$. This value ranges

\footnotetext{
${ }^{15}$ We used critical values for the FADF and inf $-t$ tests calculated for the optimal frequency $k$ for each case. These critical values are available on request.
} 
from -0.32 for the UK to -0.06 for Japan, and takes an average value of -0.17 . The $\theta$ parameter is moderately high in most cases, which implies a relatively persistent process. Only for Germany we can observe a very fast transition speed. Overall, the results appear to support the view that relative outputs are stationary around a breaking mean and that, during the sample period, some major shocks may have led to a change in the speed of mean reversion generating asymmetries that linear models cannot capture. This, however, deserves more careful analysis.

The evolution of the transition function over time is plotted in Figure 5. We can observe that for most countries, with the exception of Japan, the function fluctuates frequently around its mid-point value of 0.5 due to large shocks. For Germany the transition function moves very quickly between zero and one due to the large estimated transition speed. For the rest of the countries, this variation is smoother. The general pattern is an increase in the transition function following the shock due to WWII. This shock led relative outputs to fall substantially below equilibrium even accounting for the structural break, which results in a faster speed of mean reversion. This, to a smaller extent, is also the case after WWI. During the inter-war period the speed of transition falls as these economies expanded much faster than the US due to the impact of the Great Depression. In the absence of large shocks of this magnitude in the post-WWII period, the speed of mean reversion becomes much more stable for the great majority of countries. Only for Japan can we observe little variation around the mean with the exception of the war years.

We also plot the transition function against the lagged difference from equilibrium $v_{t-i}$ in Figure 6. We can see that the function is well defined over the range of values of $v_{t-i}$ for all the countries in the sample with the possible exception of Japan. The majority of observations are concentrated in the range of -0.2 to 0.2 , which implies deviations from equilibrium of about $20 \%$. There are also large deviations, especially negative ones, due to the observations corresponding to the WWII years. For most cases the transition is smooth with the exception of Germany where it appears as a heavy-sided function. 
In general, the evidence presented shows that both structural breaks and asymmetric convergence speeds are important in driving relative outputs. The F-test for the joint significance of the Fourier terms always rejects the null of linearity (no-breaks). These breaks account for large part of the rejections of the unit root null. In addition, asymmetries in adjustment stemming from large shocks happen to be important for all the countries with the possible exception of Japan, where our results cannot reject the null of non-convergence. In the rest of the cases the tests reject the unit root null and the results favor convergence in output to an infrequently changing mean. ${ }^{16}$

\section{Conclusions}

Theoretical models of growth have important implications for the dynamics of relative per capita output. The standard neoclassical growth model predicts that two countries that share the same structural characteristics will converge in the long run. Time series tests of convergence have been put forward as a superior alternative for testing convergence than standard cross-sectional tests. Deterministic convergence between two pairs of countries would imply that relative outputs are reverting to a mean that might be different from zero. Within this context, we argue that there are two important aspects that need to be considered when testing for convergence. On the one hand, structural breaks in the series may lead to spurious non-rejection of the null of a unit root when the process is stationary around a breaking mean. These breaks are likely to appear as a consequence of large disruptive exogenous events such as wars and crises. On the other hand, we show that the standard neoclassical growth model suggests that the speed of convergence when the economy is not in the neighborhood of the steady state is high (low) as it approaches equilibrium from below (above). In this case, transitional dynamics will be reflected in the series and mean reversion becomes faster when the economy is far below its steady

\footnotetext{
${ }^{16}$ We investigated further the reasons for the non-rejection of the null in the Japanese case. From the residuals of the FADF and LSTAR models it is clear that 1945 represents a very large outlier, which can be affecting our estimates and leading to a badly behaved transition function. When this outlier was dummied out, the results lead to a very substantial increase in the t-ratios for the null of a unit root (-3.67 for the FADF and -4.30 for the inf $-t$ test). However, we prefer no to make inference on these values as we do not know the properties of the test in the presence of dummy variables.
} 
state and slower when it is far beyond it. This would induce asymmetric mean-reversion which, if not modeled, may also lead to a loss of power of standard unit root tests.

In this paper we present unit root tests that take these two issues into account. The tests consist of fitting non-constant deterministic trends by means of a Fourier series and then applying linear and asymmetric unit root tests to the residuals. The Fourier function allows for the timing and nature (i.e. temporary or permanent) of the breaks to be endogenously determined, which allows us to classify countries depending on their relative economic performance throughout the sample. The shape of the asymmetric adjustment also matches the theoretical predictions of a standard growth model. We tabulate critical values for two versions of the test depending on the number of breaks in the series. The tests are shown to have satisfactory size and power properties.

We applied these tests to per capita output of 14 OECD countries relative to the US for the 1900-2000 period. Our results show that, for 10 cases, considering these breaks alone lead to the rejection of a unit root. In the remaining cases, considering both breaks and asymmetric adjustment leads to the rejection of the null of a unit root (non-convergence) in all cases except for Japan (where the 1945 outlier appears to play a prominent role). Both, breaks and asymmetries, are associated the large shocks in relative output generated by the 1920s depression and WWII. In several cases these breaks appear to be permanent, leading to cases of catching-up (such as in Scandinavian countries, Japan, and Italy) and falling behind (as in Australia and the UK). Overall, the results lend support for the idea that relative outputs converge in the long run to an infrequently changing mean and emphasize the importance that large disruptive events have on the dynamics of convergence. 


\section{Tables}

Table 1: Null critical values for unit root tests against stationarity for the FADF statistic

\begin{tabular}{|c|c|c|c|c|}
\hline$T=100$ & $K$ & $1 \%$ & $5 \%$ & $10 \%$ \\
\hline & 0.5 & -4.57 & -3.97 & -3.64 \\
\hline & 1 & -4.43 & -3.85 & -3.52 \\
\hline & 1.5 & -4.19 & -3.48 & -3.14 \\
\hline & 2.5 & -3.80 & -3.14 & -2.79 \\
\hline & 3 & -3.70 & -3.06 & -2.71 \\
\hline$T=250$ & 0.5 & -4.47 & -3.93 & -3.64 \\
\hline & 1 & -4.36 & -3.78 & -3.48 \\
\hline & 1.5 & -4.04 & -3.44 & -3.12 \\
\hline & 2.5 & -3.77 & -3.14 & -2.81 \\
\hline & 3 & -3.68 & -3.03 & -2.71 \\
\hline & 0.5 & -4.45 & -3.88 & -3.64 \\
\hline & 1 & -4.40 & -3.78 & -3.46 \\
\hline & 1.5 & -4.06 & -3.46 & -3.13 \\
\hline & 2.5 & -3.83 & -3.15 & -2.80 \\
\hline & 3 & -3.64 & -3.05 & -2.74 \\
\hline
\end{tabular}

Table 2: Null critical values for unit root tests against stationarity for the inf $-t$ statistic

\begin{tabular}{|c|c|c|c|c|}
\hline$T=100$ & $k$ & $1 \%$ & $5 \%$ & $10 \%$ \\
\hline & 0.5 & -4.53 & -3.96 & -3.65 \\
\hline & 1 & -4.46 & -3.86 & -3.56 \\
\hline & 1.5 & -4.18 & -3.50 & -3.15 \\
\hline & 2.5 & -3.85 & -3.18 & -2.82 \\
\hline & 3 & -3.75 & -3.10 & -2.77 \\
\hline$T=250$ & 0.5 & -4.48 & -3.94 & -3.63 \\
\hline & 1 & -4.40 & -3.79 & -3.51 \\
\hline & 1.5 & -4.05 & -3.46 & -3.14 \\
\hline & 2.5 & -3.76 & -3.16 & -2.84 \\
\hline & 3 & -3.69 & -3.08 & -2.77 \\
\hline$T=500$ & 0.5 & -4.42 & -3.89 & -3.64 \\
\hline & 1 & -4.43 & -3.81 & -3.54 \\
\hline & 1.5 & -4.07 & -3.47 & -3.16 \\
\hline & 2.5 & -3.87 & -3.16 & -2.82 \\
\hline & 3 & -3.66 & -3.07 & -2.74 \\
\hline
\end{tabular}


Table 3: Empirical size of the tests

\begin{tabular}{|c|c|c|c|c|c|c|c|c|}
\hline & \multicolumn{4}{|c|}{ FADF } & \multicolumn{4}{|c|}{ inf $-t$} \\
\hline & $k=0.5$ & $k=1$ & $k=1.5$ & $k=2.5$ & $k=0.5$ & $k=1$ & $k=1.5$ & $k=2.5$ \\
\hline & \multicolumn{8}{|c|}{$\mathrm{T}=100$} \\
\hline$\delta_{i}=1$ & 0.046 & 0.043 & 0.043 & 0.041 & 0.050 & 0.048 & 0.043 & 0.038 \\
\hline$\delta_{i}=0.5$ & 0.048 & 0.047 & 0.048 & 0.048 & 0.053 & 0.054 & 0.051 & 0.048 \\
\hline \multirow{2}{*}{$\delta_{i}=0.1$} & 0.049 & 0.049 & 0.048 & 0.049 & 0.053 & 0.053 & 0.054 & 0.054 \\
\hline & \multicolumn{8}{|c|}{$\mathrm{T}=250$} \\
\hline$\delta_{i}=1$ & 0.046 & 0.047 & 0.041 & 0.042 & 0.048 & 0.050 & 0.049 & 0.044 \\
\hline$\delta_{i}=0.5$ & 0.046 & 0.048 & 0.044 & 0.045 & 0.052 & 0.054 & 0.052 & 0.051 \\
\hline$\delta_{i}=0.1$ & 0.047 & 0.047 & 0.046 & 0.047 & 0.055 & 0.055 & 0.054 & 0.055 \\
\hline
\end{tabular}

Note: Nominal size is $5 \%$ and number of draws is 10,000 . 
Table 4: Empirical powers of unit root tests for a globally stationary LSTAR process at the $5 \%$ nominal level

\begin{tabular}{|c|c|c|c|c|c|c|c|c|c|}
\hline & \multicolumn{5}{|c|}{ FADF } & \multicolumn{4}{|c|}{ inf $-t$} \\
\hline & & $k=0.5$ & $k=1$ & $k=1.5$ & $k=2.5$ & $k=0.5$ & $k=1$ & $k=1.5$ & $k=2.5$ \\
\hline$\rho$ & $\theta$ & \multicolumn{8}{|c|}{$\delta_{1}=\delta_{2}=1$} \\
\hline-1.5 & 0.01 & 1.000 & 1.000 & 1.000 & 1.000 & 1.000 & 1.000 & 1.000 & 1.000 \\
\hline-1.5 & 0.5 & 0.874 & 0.991 & 0.994 & 0.996 & 0.947 & 0.999 & 0.999 & 0.999 \\
\hline-1.5 & 1.0 & 0.027 & 0.163 & 0.221 & 0.321 & 0.463 & 0.737 & 0.771 & 0.838 \\
\hline-1.0 & 0.01 & 0.947 & 1.000 & 1.000 & 1.000 & 0.999 & 1.000 & 1.000 & 1.000 \\
\hline-1.0 & 0.5 & 0.214 & 0.760 & 0.855 & 0.929 & 0.520 & 0.963 & 0.966 & 0.992 \\
\hline-1.0 & 1.0 & 0.002 & 0.042 & 0.067 & 0.131 & 0.222 & 0.491 & 0.514 & 0.638 \\
\hline-0.5 & 0.01 & 0.264 & 0.813 & 0.942 & 0.996 & 0.324 & 0.857 & 0.948 & 0.997 \\
\hline-0.5 & 0.5 & 0.013 & 0.126 & 0.196 & 0.362 & 0.142 & 0.435 & 0.497 & 0.689 \\
\hline-0.5 & 1.0 & 0.0003 & 0.008 & 0.028 & 0.039 & 0.06 & 0.153 & $\begin{array}{l}0.192 \\
\end{array}$ & 0.301 \\
\hline-0.1 & 0.01 & 0.006 & 0.015 & 0.039 & 0.088 & 0.001 & 0.021 & 0.053 & 0.108 \\
\hline-0.1 & 0.5 & 0.004 & 0.010 & 0.030 & 0.055 & 0.013 & 0.020 & 0.049 & 0.092 \\
\hline-0.1 & 1.0 & 0.002 & 0.007 & 0.018 & 0.033 & 0.009 & 0.016 & 0.039 & 0.070 \\
\hline$\rho$ & $\theta$ & \multicolumn{8}{|c|}{$\delta_{1}=\delta_{2}=0.1$} \\
\hline-1.5 & 0.01 & 1.000 & 1.000 & 1.000 & 1.000 & 1.000 & 1.000 & 1.000 & 1.000 \\
\hline-1.5 & 0.5 & 0.992 & 0.994 & 0.996 & 0.977 & 0.998 & 0.999 & 0.999 & 0.999 \\
\hline-1.5 & 1.0 & 0.181 & 0.223 & 0.282 & 0.346 & 0.795 & 0.827 & 0.853 & 0.878 \\
\hline-1.0 & 0.01 & 1.000 & 1.000 & 1.000 & 1.000 & 1.000 & 1.000 & 1.000 & 1.000 \\
\hline-1.0 & 0.5 & 0.829 & 0.879 & 0.928 & 0.950 & 0.978 & 0.988 & 0.993 & 0.996 \\
\hline-1.0 & 1.0 & 0.052 & 0.077 & 0.115 & 0.163 & 0.588 & 0.642 & 0.698 & 0.745 \\
\hline-0.5 & 0.01 & 0.954 & 0.983 & 0.998 & 1.000 & 0.963 & 0.987 & 0.998 & 1.000 \\
\hline-0.5 & 0.5 & 0.167 & 0.227 & 0.337 & 0.448 & 0.591 & 0.666 & 0.766 & 0.843 \\
\hline-0.5 & 1.0 & 0.011 & 0.017 & 0.035 & 0.057 & 0.266 & 0.318 & 0.403 & 0.485 \\
\hline-0.1 & 0.01 & 0.013 & 0.022 & 0.061 & 0.136 & 0.019 & 0.030 & 0.075 & 0.161 \\
\hline-0.1 & 0.5 & 0.013 & 0.020 & 0.043 & 0.075 & 0.025 & 0.037 & 0.077 & 0.138 \\
\hline-0.1 & 1.0 & 0.0007 & 0.013 & 0.026 & 0.044 & 0.020 & 0.029 & 0.063 & 0.112 \\
\hline
\end{tabular}

Note: sample size is 250 and number of draws 10,000 
Table 5: Unit root tests on output relative to the US based on a Fourier function

\begin{tabular}{|c|c|c|c|lll|}
\hline & $\hat{k}$ & $F_{\mu}(\hat{k})$ & FADF & $\theta$ & $\rho$ & inf $-t$ \\
\hline Australia & 0.50 & $\underline{56.61}$ & $-4.77^{* * *}$ & 3.59 & -0.57 & $-5.05^{* * *}$ \\
\hline Austria & 1.10 & $\underline{59.52}$ & -3.13 & 1.93 & -0.29 & $-3.92^{* *}$ \\
\hline Belgium & 1.40 & $\underline{31.60}$ & $-4.24^{* * *}$ & 2.61 & -0.27 & $-4.14^{* *}$ \\
\hline Canada & 1.10 & $\underline{34.70}$ & $-4.25^{* *}$ & 7.33 & -0.44 & $-3.81^{* *}$ \\
\hline Denmark & 2.90 & $\underline{9.19}$ & $-3.71^{* * *}$ & 1.48 & -0.31 & $-3.80^{* * *}$ \\
\hline Finland & 0.60 & $\underline{159.82}$ & $-3.74^{*}$ & 3.04 & -0.34 & $-4.24^{* *}$ \\
\hline France & 1.00 & $\underline{18.15}$ & $-3.94^{* *}$ & 1.64 & -0.25 & $-4.27^{* *}$ \\
\hline Germany & 3.60 & $\underline{19.13}$ & -2.61 & 122.80 & -0.22 & $-4.36^{* * *}$ \\
\hline Japan & 0.50 & $\underline{132.83}$ & -2.09 & 1.69 & -0.11 & -2.21 \\
\hline Italy & 0.80 & $\underline{40.44}$ & -3.57 & 2.29 & -0.23 & $-4.00^{* *}$ \\
\hline Nether. & 1.60 & $\underline{14.54}$ & $-4.33^{* * *}$ & 1.86 & -0.31 & $-4.91^{* * *}$ \\
\hline Norway & 0.10 & $\underline{114.79}$ & $-4.29 * *$ & 2.69 & -0.37 & $-4.82^{* * *}$ \\
\hline Sweden & 0.90 & $\underline{83.77}$ & $-4.25^{* *}$ & 3.46 & -0.33 & $-4.21^{* *}$ \\
\hline UK & 0.60 & $\underline{87.76}$ & $-3.67^{*}$ & 4.39 & -0.63 & $-5.01^{* * *}$ \\
\hline
\end{tabular}

Notes: $(* * *),(* *)$ and $(*)$ denote rejection of the null unit root hypothesis at the $1 \%, 5 \%$ and $10 \%$ significance level respectively. The underlined figures indicate rejection of the null of linearity at conventional significance levels. The $F_{\mu}(\hat{k})$ test is distributed as a $F$-statistic under the null hypothesis with two degrees of freedom. The critical values are taken from Table 1 of Becker et al. (2006). The optimal lag was selected optimally using the SBIC.

Table 6: Estimated Fourier function

\begin{tabular}{|c|c|c|c|c|c|c|}
\hline & $\hat{k}$ & $\begin{array}{c}\text { Coefficient } \\
\operatorname{Cos}(.)\end{array}$ & t-ratio & $\begin{array}{c}\text { Coefficient } \\
\operatorname{Sin}(.)\end{array}$ & t-ratio & $\begin{array}{c}\text { Relative } \\
\text { output }\end{array}$ \\
\hline Australia & 0.50 & 0.11 & 10.17 & -0.11 & -4.33 & $(-)$ \\
\hline Austria & 1.10 & 0.28 & 10.81 & -0.05 & -1.97 & $(-)(=)$ \\
\hline Belgium & 1.40 & 0.04 & 1.83 & 0.17 & 7.65 & $(=)$ \\
\hline Canada & 1.10 & 0.05 & 6.54 & -0.05 & -5.47 & $(-)(=)$ \\
\hline Denmark & 2.90 & 0.07 & 3.69 & -0.04 & -2.23 & $(+)(=)$ \\
\hline Finland & 0.60 & -0.28 & -13.95 & -0.16 & -5.08 & $(+)$ \\
\hline France & 1.00 & 0.14 & 4.51 & -0.12 & -3.98 & $(=)$ \\
\hline Germany & 3.60 & 0.15 & 5.64 & -0.05 & -1.64 & $(-)(=)$ \\
\hline Japan & 0.50 & -0.52 & -14.61 & -0.56 & -6.80 & $(+)$ \\
\hline Italy & 0.80 & 0.05 & 1.50 & -0.26 & -8.96 & $(+)$ \\
\hline Nether. & 1.60 & -0.04 & -1.77 & 0.15 & 5.19 & $(-)(=)$ \\
\hline Norway & 0.10 & -2.33 & -2.51 & 0.48 & 1.55 & $(+)$ \\
\hline Sweden & 0.90 & -0.09 & -5.59 & -0.16 & -11.28 & $(+)$ \\
\hline UK & 0.60 & 0.17 & 12.52 & -0.02 & -0.72 & $(-)$ \\
\hline
\end{tabular}




\section{Figures}

Figure 1: Speed of convergence for $n=0.01, g=0.02, \delta=0.05$ and $\alpha=1 / 3$

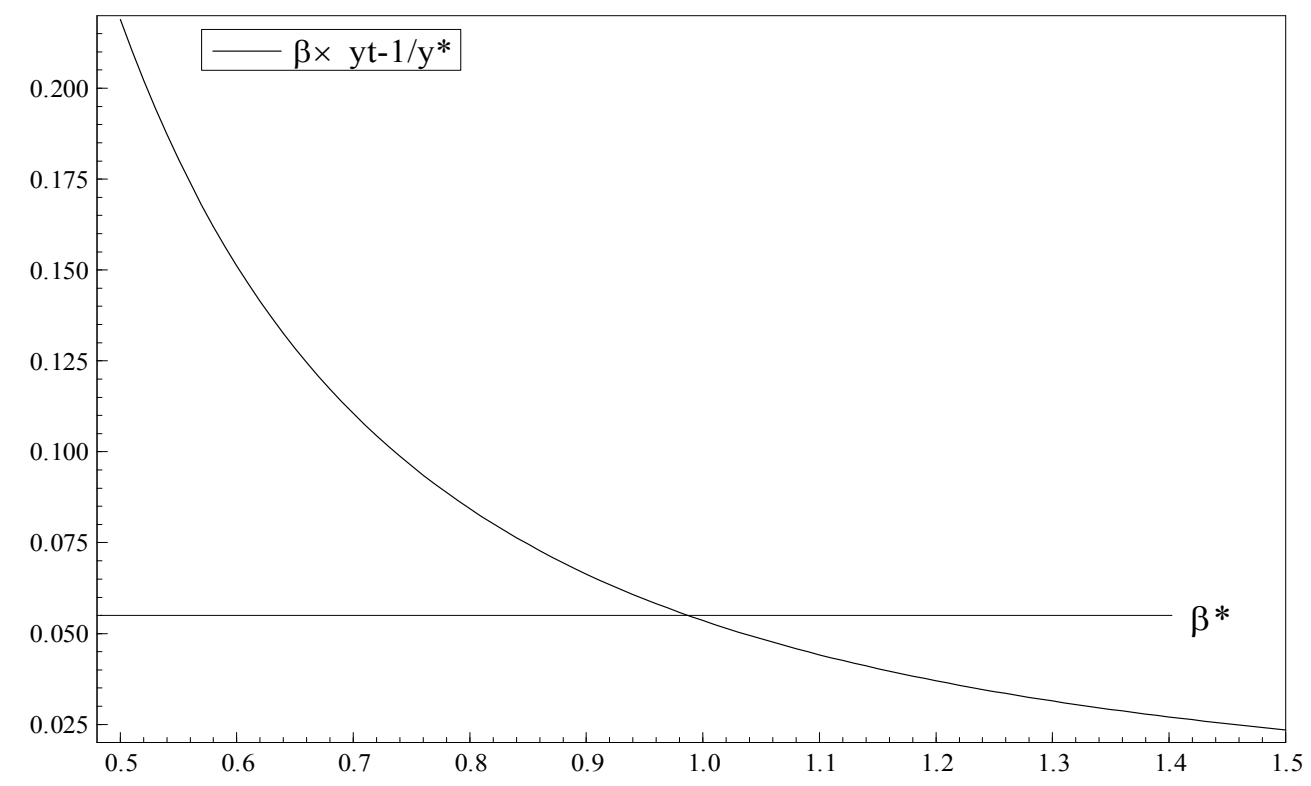

Figure 2: Fourier Function for different values of $\boldsymbol{k}$ and $\delta_{1 \text { and } 2}$

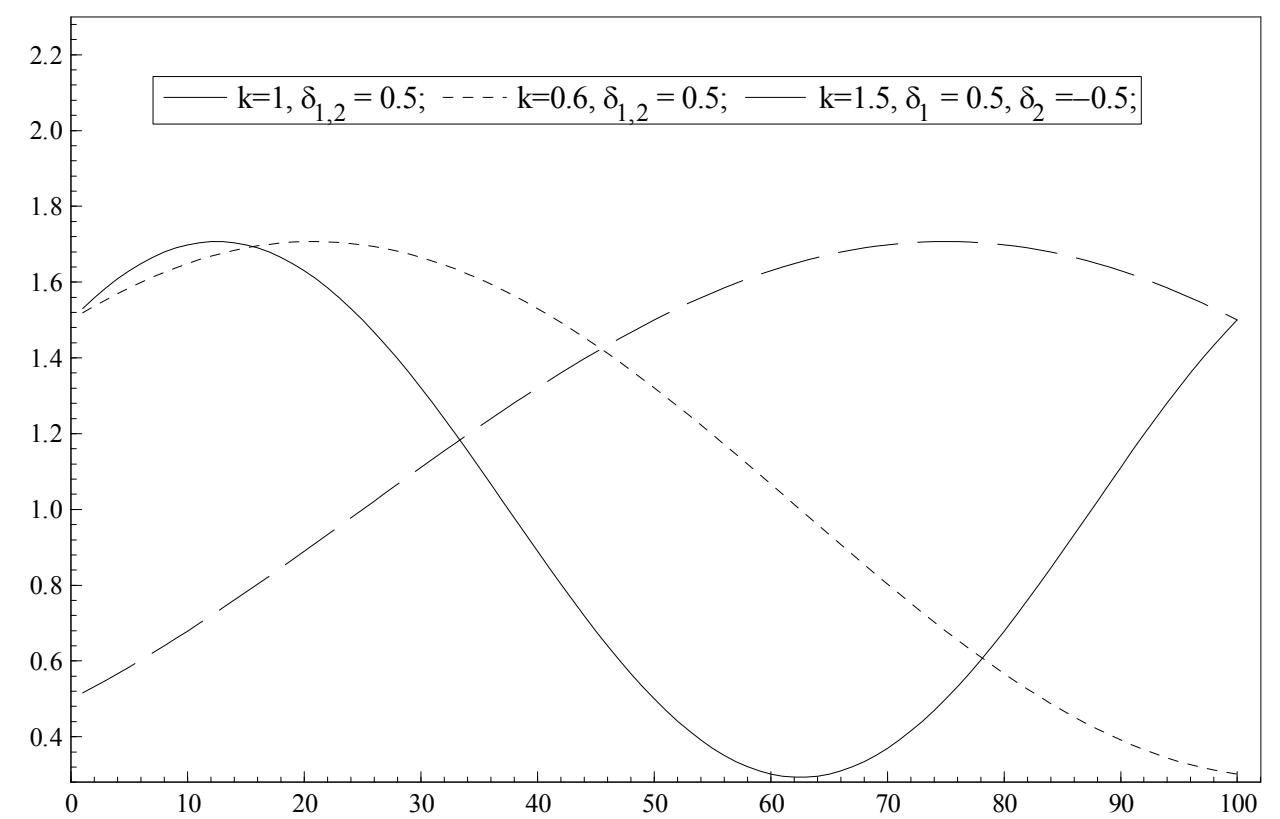


Figure 3: Output relative to the US
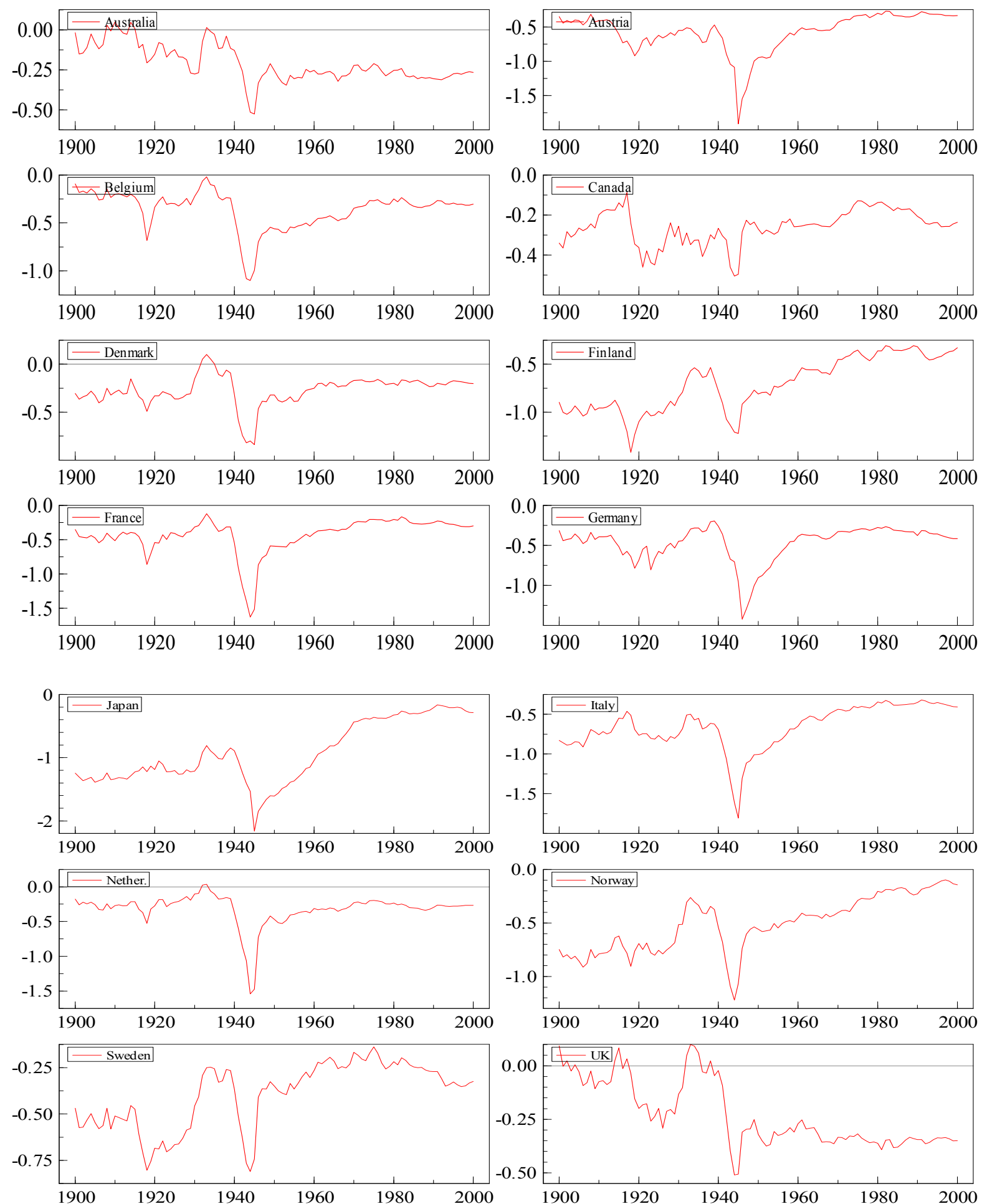
Figure 4: Relative Output and the Fourier function with fractional $k$
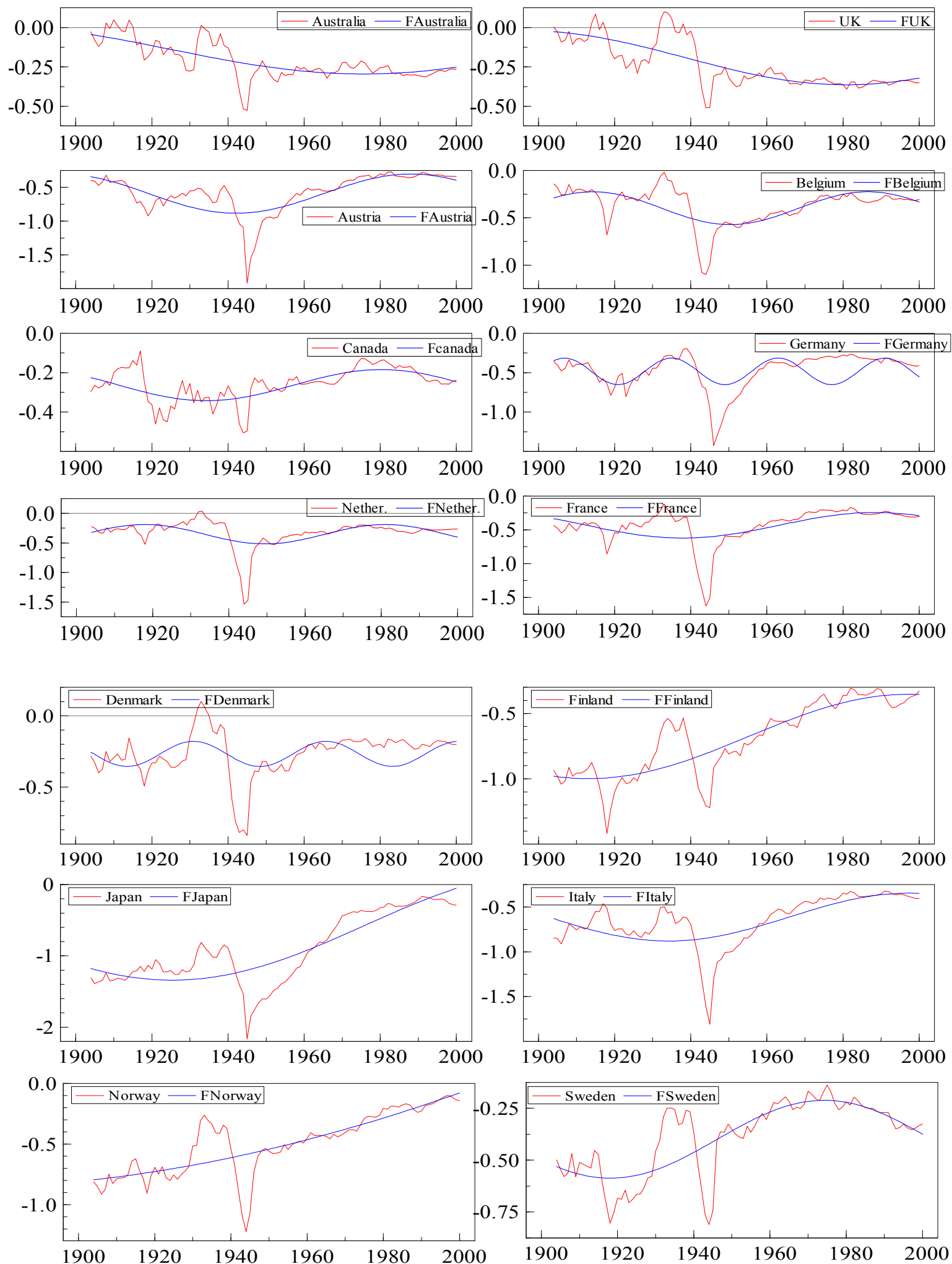
Figure 5: Transition functions over time
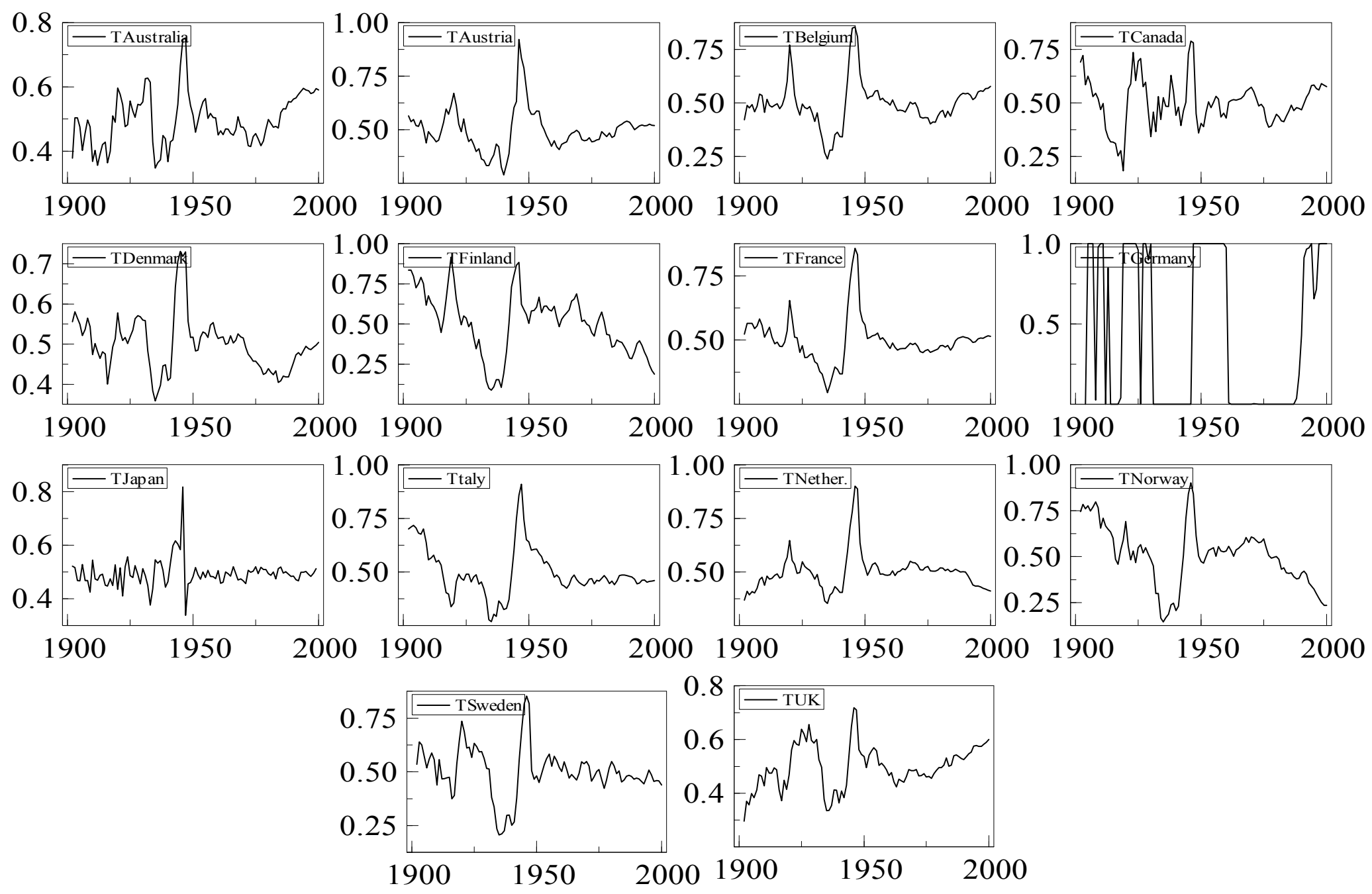
Figure 6: Transition function vs $v_{t-i}$
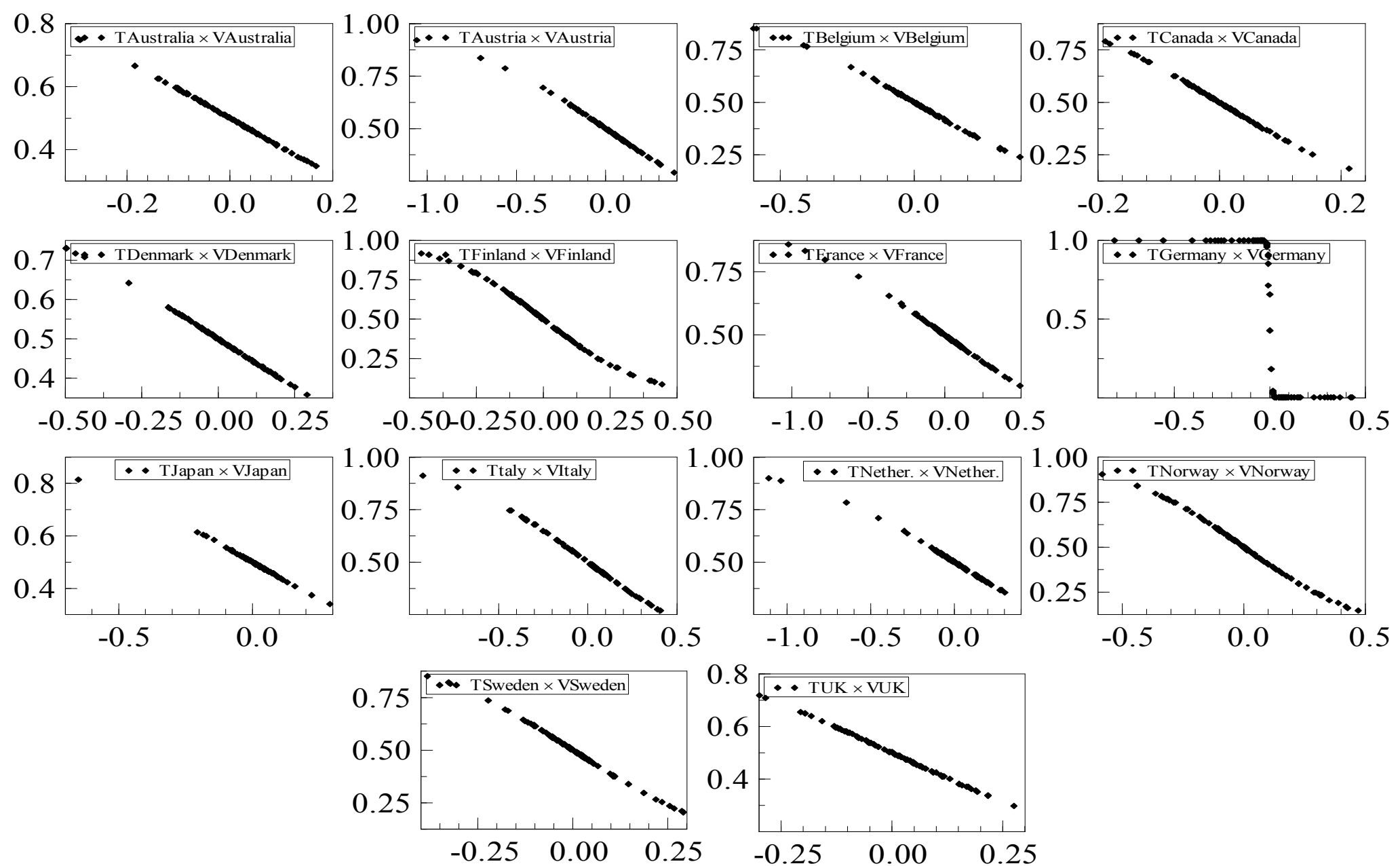


\section{References}

Bai, J. and Perron, P., 2003, Computation and analysis of multiple structural change models, Journal of Applied Econometrics 18, 1-22.

Barro, R.J. and Sala-i-Martin, X. (2004) Economic Growth. $2^{\text {nd }}$ Edition. MIT Press.

Becker, R., W. Enders and Hurn, S., 2004, A general test for time dependence in parameters, Journal of Applied Econometrics 19, 899-906.

Becker, R., W. Enders and Lee, J, 2006, A stationarity test in the presence of unknown number of smooth breaks, Journal of Time Series Analysis 27, 381-409.

Bentzen, J, 2005, Testing for catching-up periods in time-series convergence, Economics Letters 88, 333-328.

Bernard, A. and Durlauf, S.N., 1995, Convergence of international output movements, Journal of Applied Econometrics 10,97-108.

Bernard, A. and Durlauf, S.N., 1995, Interpreting tests of the convergence hypothesis, Journal of Econometrics 71, 161-173.

Binder, M., and Pesaran, M.H., 1999, Stochastic growth models and their econometric implications, Journal of Economic Growth 4, 139-183.

Camarero, M., Flores, R.G. and Tamarit, C., 2002. Multivariate time series evidence of international output convergence in Mercosur. Conference of the Society for Computational Economics, Cepremap, Paris.

Carlino, G.A. and Mills, L.O., 1993, Are U.S. regional incomes converging? A time series analysis, Journal of Monetary Economics 32, 335-346.

Carvalho, V.M. and Harvey, A.C., 2005, Growth, cycles and convergence in US regional time series, International Journal of Forecasting 21, 667-686.

Cheung, Y-W. and Garcia-Pascual, A., 2004, Testing for output convergence: a reexamination, Oxford Economic Papers 56, 45-63.

Datta, A., 2003, Time series tests of convergence and transitional dynamics, Economics Letters 81, 233-240.

Durlauf, S.N., Johnson, P.A. and Temple, J.R.W., 2006, Growth econometrics, in Handbook of Economic Growth, P. Aghion and S. Durlauf, eds., Amsterdam: North Holland, 2006. 
Evans, P., 1998, Panel data to evaluate growth theories, International Economic Review 39, 295-306.

Landon-Lane, J.S. and Robertson, P.E., 2004, WWII and long-run convergence in the OECD, Econometric Society North American Summer Meeting.

Li, Q. and Papell, D.H., 1999, Convergence of international output: time series evidence for 16 OECD countries, International Review of Economics and Finance 8, 267-280.

Loewy M.B. and Papell, D.H., 1996, Are U.S. regional incomes converging? Some further evidence, Journal of Monetary Economics 38, 587-598.

Ludlow, J. and Enders, W., 2000, Estimating non-linear ARMA models using Fourier coefficients, International Journal of Forecasting 16, 333-347.

Luginbuhl, R., and Koopman, S.J., 2004. Convergence in European GDP series: a multivariate common converging trend-cycle decomposition, Journal of Applied Econometrics 19, 611-638.

Maddison, A., 1995, Monitoring the world economy 1820-1992, OECD Development Centre, Paris.

Mathunjwa, J.S. and Temple, J.R.W., 2006, Convergence behaviour in exogenous growth models. Discussion Paper 06/590, University of Bristol.

Park, J.Y. and Shintani, M., 2005, Testing for a unit-root against transitional autoregressive models. Working Paper 05-W10, Department of Economics, Vanderbilt University.

Perron, P, 1990, Testing for a unit root in a time series with changing mean, Journal of Business of Economic and Statistics 8, 153-162.

Pesaran, M.H., 2007, A pair-wise approach to testing for output and growth convergence, Journal of Econometrics 138, 312-355.

Solow, R.M., 1956, A contribution to the theory of economic growth, Quarterly Journal of Economics 70, 65-94.

St. Aubyn, M., 1999, Convergence across industrialised countries (1890-1989): new results using time series methods, Empirical Economics 24, 23-44.

Zivot, E. and Andrews, D.W.K., 1992, Further evidence on the great crash, the oil price shocks and the unit root hypothesis, Journal of Business of Economic and Statistics 10, 251-270. 